\title{
Regulation and Role of Connective Tissue Growth Factor in AngII-Induced Myocardial Fibrosis
}

\author{
Nicole L. Rosin, ${ }^{*}$ Alec Falkenham, ${ }^{*}$ Mryanda J. Sopel, ${ }^{*}$ Timothy D.G. Lee, ${ }^{* \dagger \neq}$ and Jean-Francois Légaré ${ }^{* \dagger \ddagger}$ \\ From the Departments of Pathology, ${ }^{*}$ Surgery, ${ }^{\dagger}$ and Microbiology and Immunology, ${ }^{\ddagger}$ Dalhousie University, Halifax, Nova Scotia, Canada
}

Accepted for publication

November 15, 2012.

Address correspondence to

Jean-Francois Légaré, M.D.,

Department of Surgery, New

Halifax Infirmary, 1796

Summer St,

Rm 2269, Halifax, NS B3H

3A7, Canada. E-mail: jean.

legare@cdha.nshealth.ca.

\begin{abstract}
Exposure of rodents to angiotensin II (AngII) is a common model of fibrosis. We have previously shown that cellular infiltration of bone marrow-derived progenitor cells (fibrocytes) occurs before deposition of extracellular matrix and is associated with the production of connective tissue growth factor (CTGF). In the present study, we characterized the role of CTGF in promoting fibrocyte accumulation and regulation after AngII exposure. In animals exposed to AngII using osmotic minipumps (2.0 $\mu \mathrm{g} / \mathrm{kg}$ per min), myocardial CTGF mRNA peaked at 6 hours (21-fold; $P<0.01$ ), whereas transforming growth factor- $\beta$ (TGF- $\beta$ ) peaked at 3 days (fivefold; $P<0.05$ ) compared with saline control. Early CTGF expression occurred before fibrocyte migration (1 day) into the myocardium or ECM deposition (3 days). CTGF protein expression was evident by day 3 of AngII exposure and seemed to be localized to resident cells. Isolated cardiomyocytes and microvascular endothelial cells responded to AngII with increased CTGF production (2.1-fold and 2.8-fold, respectively; $P<0.05$ ), which was abolished with the addition of anti-TGF- $\beta$ neutralizing antibody. The effect of CTGF on isolated fibrocytes suggested a role in fibrocyte proliferation (twofold; $P<0.05)$ and collagen production $(2.3$-fold; $P<0.05)$. In summary, we provide strong evidence that AngII exposure first resulted in Smad2-dependent production of CTGF by resident cells ( 6 hours), well before the accumulation of fibrocytes or TGF- $\beta$ mRNA up-regulation. In addition, CTGF contributes to fibrocyte proliferation in the myocardium and enhances fibrocyte differentiation into a myofibroblast phenotype responsible for ECM deposition. (Am J Pathol 2013, 182: 714-726; http:// dx.doi.org/10.1016/j.ajpath.2012.11.014)
\end{abstract}

Myocardial fibrosis is a common pathologic feature of many cardiovascular disorders characterized by overabundant deposition of extracellular matrix (ECM) molecules in combination with a deficit in ECM degradation. ${ }^{1,2}$ The excess ECM protein results in loss of contractility and increased stiffness, ultimately leading to organ dysfunction and endstage heart failure. ${ }^{1,3}$ Current understanding of the molecular mechanisms culminating in increased matrix deposition is incomplete and warrants further investigation into the pathways involved.

One molecule, angiotensin II (AngII), has been implicated in the development of fibrosis in the myocardium as well as in other fibrotic disorders. ${ }^{4,5}$ This hormone is a member of the renin-angiotensin system and thus is involved in blood pressure regulation; however, it has also been correlated with conditions that lead to organ fibrosis. ${ }^{6,7}$ Exogenous administration of AngII to rodents via subcutaneous osmotic pump has become a well-established model resulting in myocardial fibrosis and functional deterioration. 8,9

Recent evidence published by us and others has demonstrated that AngII exposure leads to an influx in hematopoietic progenitor cells, termed "fibrocytes," into the myocardium. This occurs before ECM deposition. ${ }^{9-11}$ Fibrocytes possess both hematopoietic markers (CD34, CD45, and CD133) and mesenchymal markers (collagen type I [COL1], fibronectin, and vimentin). ${ }^{12,13}$ Supporting evidence for the involvement of fibrocytes has been described in fibrotic disorders of the lung, kidney, liver, and skin. ${ }^{14-17}$ While increasing evidence confirms the importance of fibrocytes in fibrotic conditions, there remains a paucity of mechanistic information such as the tissue microenvironment with which these cells interact and the cytokine signaling that elicits their contribution to ECM production.

Supported in part by grant 44122 from the Canadian Institute of Health Research (J.F.L.). 
The current paradigm concerning profibrotic signaling suggests that one of the first molecules involved in fibrosis development after AngII exposure is transforming growth factor- $\beta$ (TGF- $\beta$ ). ${ }^{18,19}$ It has been suggested that TGF $\beta$ interacts directly with cardiomyocytes, which then produce other growth factors such as connective tissue growth factor (CTGF) ${ }^{20}$ Recent studies have suggested that both the well-described TGF- $\beta$ downstream regulation via the SMAD signaling pathway and a SMAD-independent TGF- $\beta$ signaling pathway mediate up-regulation of $\mathrm{CTGF}^{21,22} \mathrm{In}$ transgenic rodent models, selective overexpression of CTGF in fibroblasts results in increased systemic tissue fibrosis. ${ }^{23} \mathrm{In}$ addition, increased levels of CTGF have been correlated with the development of fibrotic diseases including dermal, renal, liver, pulmonary, and cardiac fibrosis. ${ }^{9,24,25}$ Because of its strong link to fibrotic diseases, CTGF has also been suggested as a biomarker for fibrosis. ${ }^{24,26}$ Notwithstanding this evidence, a direct causal link between CTGF and fibrosis development after AngII exposure has yet to be established.

In the present study, we characterized the effects of AngII exposure in vivo on CTGF levels in the myocardium and in relation to infiltrating fibrocytes. We demonstrate for the first time that CTGF is the first profibrotic cytokine to be upregulated by resident cells in response to AngII exposure, through TGF- $\beta$-dependent signaling. We also provide evidence that in response to CTGF, infiltrating fibrocytes are capable of contributing to the process of ECM deposition and thereby to fibrosis development. We also show that this up-regulation depends on TGF- $\beta$ signaling in the form of early Smad2 phosphorylation.

\section{Materials and Methods}

Animals

All work was performed in accordance with the Canadian Council on Animal Care and approved by the local Committee on Laboratory Animals. Male C57Bl/6 and CAG-EGFP (006567) transgenic mice aged 7 to 8 weeks were purchased from The Jackson Laboratory (Bar Harbor, ME) and were housed within the Carleton Animal Care Facility at Dalhousie University. Mice were provided food and water ad libitum for 1 week before experimentation.

\section{GFP Chimeric Animals}

Chimeric animals were generated by transplanting bone marrow constitutively expressing green fluorescent protein (GFP) into lethally irradiated mice, as previously described. ${ }^{9,27}$ Bone marrow cells were harvested from 8-week-old GFP transgenic mice in a C57B1/6 background that ubiquitously express GFP under control of the CAG promoter. Recipient mice were irradiated with two doses of $5.5 \mathrm{~Gy}$, and unfractionated $\mathrm{GFP}^{+}$bone marrow cells $\left(1 \times 10^{6}\right.$ cells) were injected via tail vein. Engraftment was evaluated 8 weeks after transplantation by collecting peripheral blood cells and evaluating the frequency of $\mathrm{GFP}^{+}$cells relative to total peripheral nucleated cells. Only animals with engraftment of greater than $60 \% \mathrm{GFP}^{+}$cells were used for further treatment.

\section{AngII Infusion}

Mini osmotic pumps containing AngII or saline solution were implanted in animals under general anesthesia as previously reported. ${ }^{9}$ In brief, animals were anesthetized using isoflurane (Baxter Healthcare Corp., New Providence, $\mathrm{NJ}$ ) in oxygen, at which point a 1- to 2-cm midscapular skin incision was made and an Alzet mini osmotic pump (Alzet Corp., Palo Alto, CA) was inserted subcutaneously. Animals were randomly assigned to receive either $2.0 \mu \mathrm{g} / \mathrm{kg}$ per min AngII (Sigma-Aldrich Corp., St. Louis, MO) or a vehicle control of saline solution. The pumps remained in place for 6 or 12 hours or 1,3 , or 7 days, during which the animals were provided food and water ad libitum and observed for signs of morbidity.

\section{Tissue Harvest}

Hearts from experimental animals were harvested and weighed, then divided into three sections along the vertical axis. The base section of the heart was processed for histologic examination, and the other two pieces were snap frozen immediately for molecular analysis.

\section{Cell Isolation and Culture}

\section{Fibrocytes}

Peripheral blood mononuclear cells (PBMCs) and bone marrow cells were isolated from naïve mice or mice exposed to AngII for 3 days. In brief, blood was collected in heparincontaining syringes via cardiac puncture and was centrifuged. The layer containing PBMCs was isolated and washed, and residual red blood cells were lysed using ammonium chloride solution. Bone marrow cells were removed from the tibias and femurs by flushing with $10 \mathrm{~mL}$ Dulbecco's PBS (Invitrogen Corp., Carlsbad, CA) after removal of the bone ends. Hearts from mice infused with AngII for 3 days were harvested under sterile conditions and used for cell isolation as previously described. ${ }^{9}$ In brief, hearts were mechanically and enzymatically digested in a collagenase solution $(50 \mathrm{mg} / \mathrm{mL}$ collagenase II; Cedarlane Laboratories, Ltd., Burlington, ON, Canada) in Gibco RPMI 1640 medium (Life Technologies Corp., Burlington, ON, Canada) at $37^{\circ} \mathrm{C}$, with agitation for 45 minutes. Cell isolates were washed in complete RPMI containing $10 \%$ heatinactivated fetal bovine serum, $2 \mathrm{mmol} / \mathrm{L}$ L-glutamine, $100 \mathrm{mg} / \mathrm{mL}$ streptomycin, and $100 \mathrm{U} / \mathrm{mL}$ penicillin. Cells were then plated in $\mathrm{T} 25$ flasks coated with $0.1 \%$ gelatin, incubated for 3 days at $37^{\circ} \mathrm{C}$ and $5 \% \mathrm{CO}_{2}$, at which point all nonadherent cellular debris was removed and medium was replenished. 


\section{Cardiomyocytes}

Neonatal cardiomyocytes were isolated from day-old C57B1/6 pups as reported previously. ${ }^{28}$ In short, pups were decapitated, and hearts were excised and mechanically and enzymatically digested in $0.25 \%$ trypsin-EDTA for 20 minutes. Cell isolates were washed in complete Dulbecco's modified Eagle's medium containing 20\% fetal bovine serum, $2 \mathrm{mmol} / \mathrm{L}_{\mathrm{L}-\text { glutamine, }} 100 \mu \mathrm{mol} / \mathrm{L}$ nonessential amino acids, $100 \mathrm{mg} / \mathrm{mL}$ streptomycin, and $100 \mathrm{U} / \mathrm{mL}$ penicillin and allowed to differentially adhere to a T75 flask for 2 hours. Cardiomyocytes were then collected from the suspension and plated on $0.1 \%$ gelatin-coated six-well plates.

\section{Endothelial Cells}

The microvascular endothelial cell line b.End3 (American Type Culture Collection, Manassas, VA) was cultured according to the supplier's instructions using Dulbecco's modified Eagle's medium containing 10\% heat-inactivated fetal bovine serum, $2 \mathrm{mmol} / \mathrm{L}$ L-glutamine, $100 \mathrm{mg} / \mathrm{mL}$ streptomycin, and $100 \mathrm{U} / \mathrm{mL}$ penicillin.

Isolated fibrocytes, neonatal cardiomyoctes, and endothelial cells were serum starved overnight before being treated with either AngII (100 nmol/L), AngII plus anti-TGF- $\beta$ neutralizing antibody $(15 \mu \mathrm{g} / \mathrm{mL}$; R\&D Systems, Inc., Minneapolis, MN), ${ }^{29,30}$ sterile filtered full-length recombinant human CTGF produced in E. coli $(125 \mathrm{ng} / \mathrm{mL}$; CRC022B; Cell Sciences, Canton, MA), or PBS as vehicle control.

\section{Histologic Analysis}

Hearts were processed for histologic assay by either fixing with $10 \%$ formalin for 24 hours or protecting with sucrose/OCT followed by snap freezing. Formalin-fixed tissues were paraffin embedded and serially sectioned on a $5-\mu \mathrm{m}$ microtome. Basic myocardial histologic features and cellular infiltration were examined using heart cross-sections stained with $\mathrm{H} \& \mathrm{E}$. Immunohistochemistry for CTGF (Abcam, Inc., Cambridge, MA) and Ki-67 (DakoCytomation, Mississauga, ON, Canada) was performed on paraffin-embedded tissues, which were deparaffinized and treated for antigen retrieval before staining. In brief, endogenous peroxidases were quenched using 3\% hydrogen peroxide; endogenous biotin was blocked (Dako Biotin Blocking System; DakoCytomation); and nonspecific staining was blocked using normal goat serum. Sections were incubated with primary antibody, followed by a specific biotinconjugated secondary antibody. The antibody complexes were then conjugated to an avidin-biotin complex (Vectastain ABC kit; Vector Laboratories, Inc., Burlington, CA) and developed using 3,3'-diaminobenzidine as the chromogen (DAB; DakoCytomation). Light microscopy was performed; pictures were captured and analyzed using Adobe Photoshop 5.0.

\section{Immunofluorescence Staining}

Either isolated cells were plated on coverslips overnight, fixed in $4 \%$ paraformaldehyde, and permeabilized with $0.03 \%$
Triton X-100 or tissue sections were blocked against nonspecific antibody binding with $10 \%$ normal goat serum and stained for CD45 (BD Biosciences, Mississauga, ON, Canada), COL1 (Rockland, Inc., Gilbertsville, PA), cardiac troponin I (CTnI; Abcam), GFP (Abcam), $\alpha$-smooth muscle actin ( $\alpha$-SMA; Sigma-Aldrich), or CD133 (Abcam). Antibodies were detected using anti-host-specific Alexa fluorescently labeled secondary antibodies (Invitrogen), and nuclei were counterstained with Hoescht stain (Sigma-Aldrich). Images were captured using an Axiovert 200 inverted microscope (Carl Zeiss GmbH, Gottingen, Germany) with a Hamamatsu ORCA-R2 digital camera (Hamamatsu Photonics, Hamamatsu, Shizuoka, Japan) with an AttoArc 2 HBO 100W lamp (Carl Zeiss).

\section{Immunoblotting}

Western blot analysis was performed on samples isolated from snap-frozen heart sections. Sections were homogenized in radioimmunoprecipitation assay buffer $(150 \mathrm{mmol} / \mathrm{L}$ $\mathrm{NaCl}, 50 \mathrm{mmol} / \mathrm{L}$ Tris- $\mathrm{HCl}$ base, $0.1 \%$ SDS, $0.1 \%$ Triton $\mathrm{X}-100$, and $0.5 \%$ deoxycholic acid) with protease inhibitors added $(1 \mathrm{mmol} / \mathrm{L}$ phenylmethylsulfonyl fluoride, $5 \mu \mathrm{g} / \mathrm{mL}$ aprotinin, $5 \mu \mathrm{g} / \mathrm{mL}$ leupeptin, $5 \mu \mathrm{g} / \mathrm{mL}$ pepstatin $\mathrm{A}$, and $2 \mathrm{mg} / \mathrm{mL}$ iodoacetamide). Samples were then denatured by boiling with Laemmli sample buffer. Protein was separated on a $12 \%$ SDS-PAGE gel and transferred to an Immobilon polyvinylidene difluoride membrane (Millipore Corp., Bedford, MA). Membranes were incubated with 5\% skim milk in buffer for 1 hour before incubation with anti-CTGF (Abcam), Smad2/3 (Cell Signaling Technology, Beverly, MA), phosphoSmad2 (Cell Signaling Technology), $\beta$-tubulin (loading control; Sigma-Aldrich), or $\beta$-actin (loading control; SigmaAldrich) antibody overnight at $4^{\circ} \mathrm{C}$. Blots were developed using horseradish peroxidase-linked goat anti-rabbit $\mathrm{IgG}$ (Vector Laboratories) and an Amersham ECL kit (GE Healthcare UK, Ltd, Buckinghamshire, UK).

\section{Flow Cytometry}

Cell surface expression of CD45 and cytosolic expression of vimentin and $\mathrm{CTnI}$ was determined using flow cytometry. In brief, isolated PBMCs and bone marrow cells were incubated with a monoclonal rat anti-CD45 antibody (CL9446AP; Cedarlane Laboratories), followed by fluorescein isothiocyanate-conjugated goat anti-rat IgG2b (Cedarlane Laboratories) secondary antibody. Cells were then permeabilized using a commercial kit (BD Biosciences) and incubated with PerCP conjugated monoclonal mouse vimentin antibody (RV202; Santa Cruz Biotechnology, Inc., Santa Cruz, CA). Isolated neonatal cardiomyocytes were incubated with polyclonal rabbit anti-CTnI, followed by an Alexa Fluor 488-conjugated goat anti-rabbit IgG (Invitrogen) secondary antibody. After antibody incubations, cells were fixed in $1 \%$ formalin solution for storage before analysis. Within 5 days of labeling, cells were analyzed using a flow cytometer (BD 
FACScalibur; BD Biosciences). Findings were confirmed using isotype controls: CD45, rat IgG2b (eBioscience, Inc., San Diego, CA); vimentin-PerCP, IgG1-PerCP (Santa Cruz Biotechnology); and CTnI, rabbit IgG (Sigma-Aldrich). A secondary-only control was used to confirm the absence of nonspecific binding of the secondary antibody.

\section{Relative Real-Time qPCR}

Total RNA was isolated from snap-frozen heart sections using TRIzol (Invitrogen, Carlsbad, CA) according to the manufacturer's protocol. First strand cDNA was synthesized from RNA using an iScript cDNA Synthesis Kit (Biorad, Hercules, CA). Real-time quantitative PCR (qPCR) was completed using iQ SYBR Green supermix, and the iQ Multicolor Real-Time PCR Detection System thermal cycler (both from Bio-Rad Laboratories, Inc., Hercules, CA) was used for detection. Efficiency curves and no-template control samples were run with each sample thermocycling. Melt curves were run after cycling to ensure target specificity. Primers were designed against mRNA sequences of CTGF (forward, 5' -TCAACCTCAGACACTGGTTTCG-3'; reverse, $5^{\prime}$-TAGAGCAGGTCTGTCTGCAAGC- $3^{\prime}$ ), TGF- $\beta$ (forward, 5'-GGTCTCCCAAGGAAAGGTAGG-3'; reverse, 5'-CTCTTGAGTCCCTCGCATCC-3'), COL1A1 (forward, 5'-CAACAGTCGCTTCACCTACAGC-3'; reverse, 5'-GTGGAGGGAGTTTACACGAAGC-3'), and $18 \mathrm{~S}$ ribosomal RNA (forward, 5'-TCAACTTTCGATGGTAGTCGCCGT-3'; reverse, 5'-TCCTTGGATGTGGTAGCCGTTTCT-3'). Expression was normalized to the $18 \mathrm{~S}$ ribosomal gene using the Pfaffl method.

\section{Proliferation Assays}

An MTT assay for assessment of relative cellular proliferation was performed according to the manufacturer's instructions (Invitrogen). In brief, cells were plated in 96-well tissue culture plates and allowed to adhere overnight before stimulation. Cells were stimulated for 24 hours, at which point MTT reagent was added for 4 hours, followed by SDS-HCl solution for 18 hours to stop the reaction. Samples were mixed, and absorbance was read at $570 \mathrm{~nm}$.

Relative proliferation was also assessed via immunofluorescent staining of Ki-67 proliferation marker in cells plated on gelatin-coated coverslips. Cells were allowed to reach $50 \%$ confluence and then stimulated for 24 hours, at which point cells were fixed using $4 \%$ paraformaldehyde for 10 minutes at room temperature. Nonspecific binding was blocked using secondary host serum, and coverslips were incubated overnight at $4^{\circ} \mathrm{C}$ with anti-Ki-67 antibody. Bound antibody was detected using anti-host-specific Cy3 fluorescently labeled secondary antibodies (Invitrogen), and nuclei were stained with Hoescht dye. Images were captured using an Axiovert 200 inverted microscope (Carl Zeiss) with a Hamamatsu ORCA-R2 digital camera (Hamamatsu Photonics) with an AttoArc 2 HBO 100W lamp (Carl Zeiss).
Relative proliferation was assessed by counting the number of $\mathrm{Ki}-67-$ positive nuclei relative to the total number of nuclei in five random fields of view at $\times 20$ magnification.

\section{Scratch Assay}

Fibrocytes were isolated as previously described and cultured to $80 \%$ confluence on six-well plates. A sterile pipette tip was used to remove cells from a strip in the middle of the well. Images were captured at $\times 10$ magnification immediately $(0$ hours) or after 16 hours of culture with CTGF or with PBS as control. Leading edges of the cell fronts were demarcated, and the in-between distance was semiquantified using a pixelcount method. The relative distance was calculated as a fraction of the distance recovered by cells compared with control.

\section{Statistical Analysis}

Data are given as means \pm SEM. One-way analysis of variance was completed using the Bonferroni posttest to compare the experimental groups with the saline control group. All qPCR results were evaluated on the basis of the one-sample $t$-test to compare changes in relative expression. All statistical calculations were computed using GraphPad PRISM software version 4 (GraphPad Software, Inc., San Diego, CA), and significance was determined at $P \leq 0.05$.

\section{Results}

Bone Marrow-Derived Progenitors Are Mobilized from Bone Marrow and Infiltrate Into Myocardium after AngII Exposure

Previous work from our laboratory has demonstrated that AngII exposure results in substantial multifocal areas of cellular infiltration within the myocardium by 1 day. ${ }^{9}$ This cellular infiltration is followed by substantial collagen deposition in areas of infiltration over 3 to 7 days of AngII exposure. GFP chimeric mice that constitutively express enhanced GFP under control of the actin promoter in bone marrow-derived cells were used initially to compare animals exposed to AngII or saline control. Chimeric mice exposed to AngII for 3 days were found to have a significant percentage of infiltrating cells in the myocardium, identified in H\&Estained sections, which were $\mathrm{GFP}^{+}$when compared with saline control (Figure 1, A, B, E, and F), suggesting that bone marrow-derived cells are the predominant cell type. Immunofluorescence was used to show that infiltrating cells also expressed $\alpha$-SMA, which co-localized with GFP in AngIIexposed animals; however, co-labeled cells were absent from saline-treated animals (Figure 1, C, D, G, and H). CD133, a marker of progenitor cells, was observed to colocalize with $\mathrm{GFP}^{+}$cells using confocal microscopy (Figure 1, I-K). Similarly, COLI expressed by mesenchymal cells such as myofibroblasts co-localized with $\mathrm{GFP}^{+}$cells as well as resident fibroblasts and ECM noted throughout the 

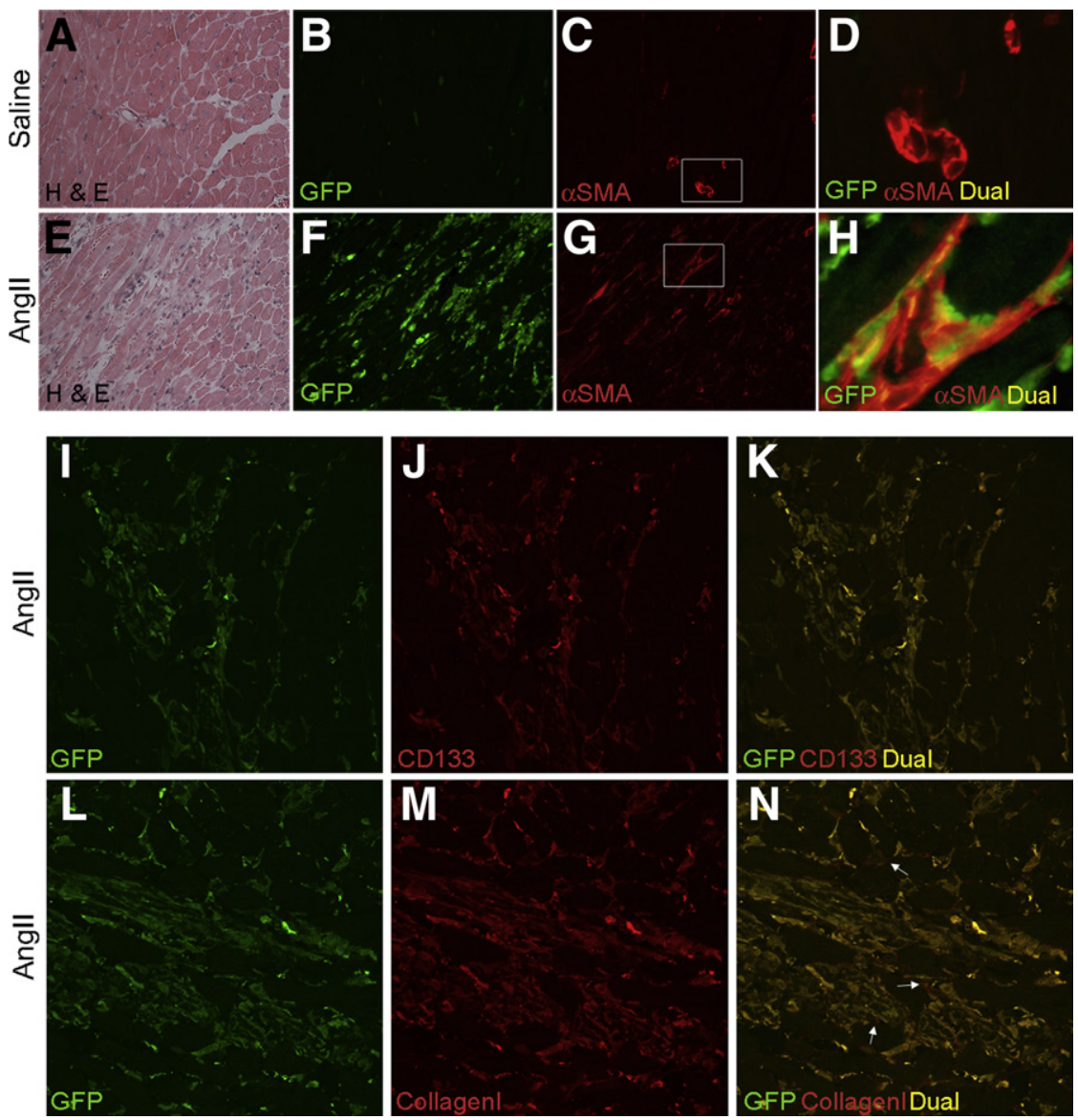

Figure 1 Fibrocyte infiltration. Chimeric animals with transplanted $\mathrm{GFP}^{+}$bone marrow cells received saline $(\mathbf{A}-\mathbf{D})$ or AngII $(\mathbf{E}-\mathbf{N})$ for 3 days. Areas containing infiltrating cells were identified using H\&E stain ( $\mathbf{A}$ and $\mathbf{E}$ ) and characterized via immunofluorescent staining for GFP (B, F, I, and $\mathbf{L}$ ) $\alpha$-SMA (C and G), CD133 (J), and COL1 (M). Merged images of green and red channels show dual staining indicating $\mathrm{GFP}^{+} / \alpha-\mathrm{SMA}^{+}(\mathbf{D}$ and $\mathbf{H}), \mathrm{GFP}^{+} /$ $\mathrm{CD} 133^{+}(\mathrm{K})$, and $\mathrm{GFP}^{+} / \mathrm{COL11}{ }^{+}(\mathrm{N})$ cells in the area of infiltration. Arrows in $\mathbf{N}$ indicate areas of uniquely $\mathrm{COL}^{+}$staining. Original magnification $\times 40(\mathbf{A}-\mathbf{C}, \mathbf{E}-\mathbf{G}) ; \times 240(\mathbf{D}$ and $\mathbf{H})$; and $\times 63$ confocal magnification $(\mathbf{I}-\mathbf{N})$, with representative images shown. $n=3$. myocardium (Figure 1, L-N). Together, these findings confirm our previous work that suggested that a significant percentage of myocardial infiltrating cells are fibrocytes known to express bone marrow (hematopoietic-GFP, CD133) and mesenchymal markers ( $\alpha$-SMA and COL1). ${ }^{9,31}$ Flow cytometry was used to identify double-positive fibrocytes in the circulation. The percentage of CD $45^{+}$and vimentin ${ }^{+}$cells, indicative of fibrocytes in PBMCs, was significantly higher in animals exposed to AngII when compared with saline-treated controls (Figure 2, A and B). Considered together, AngII infusion resulted in early mobilization of fibrocytes from the bone marrow into the circulation and significant migration to the myocardium within 3 days of exposure.

\section{CTGF Is the First Profibrotic Cytokine Noted in Myocardium after AngII Exposure}

Previous work by us and by others has suggested that TGF- $\beta$ and CTGF may be the predominant profibrotic cytokines associated with AngII-dependent myocardial fibrosis., ${ }^{9,32}$ Increased numbers and additional time points were added to historic data. ${ }^{9}$ Expression of CTGF within the myocardium relative to both housekeeping gene and saline control was significantly increased (23-fold) as early as 6 hours after AngII exposure $(P<0.01)$, preceding myocardial cellular infiltration or ECM deposition, which were significant by 1 and 3 days, respectively. ${ }^{9,31}$ CTGF mRNA levels were noted to drop off at 12 hours before increasing again at 24 hours by 19-fold $(P<0.01)$ (Figure 3A). As the second wave of CTGF expression occurred, there was a concurrent fourfold increase in TGF- $\beta$ mRNA levels, which reached significance at 24 hours of AngII exposure and peaked at 3 days, compared with saline control $(P<0.01)$ (Figure $3 \mathrm{~B})$. The increase in CTGF expression when compared with TGF- $\beta$ was earlier and several fold higher, suggesting a role for CTGF in the subsequent fibrosis development (Figure 3C). Although there was no change in TGF- $\beta$ mRNA expression in the first 12 hours of AngII exposure, early downstream activation of the TGF- $\beta$ pathway was observed; Smad 2 phosphorylation in relation to total $\mathrm{Smad} 2 / 3$ protein levels increased significantly by 6 hours (Figure 3, D and E). Smad 2 phosphorylation concomitant with CTGF mRNA expression suggests that the early peak in CTGF was at least in part TGF- $\beta$-dependent. Up-regulation of CTGF expression was confirmed by a significant increase in the presence of CTGF protein, relative to saline controls, at 3 days of AngII exposure by Western blot analysis of cardiac extracts (Figure 3, F and G). Most of the CTGF seemed to be localized to the cardiomyocytes and not the infiltrating cells, suggesting that resident cells may be a source of early CTGF production (Figure 3, H and I). 

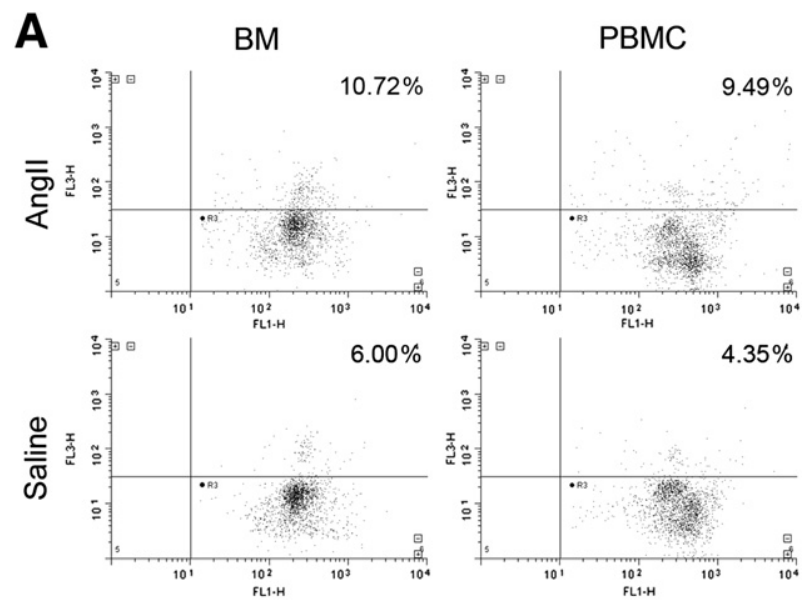

B

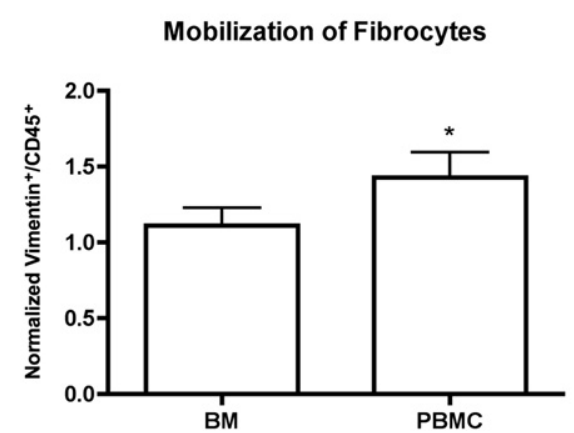

Figure 2 Fibrocyte mobilization. A: Animals received saline as control or AngII for 3 days, and bone marrow (BM) and PBMCs were isolated for assessment of CD45 and vimentin presence via flow cytometry. B: Quantification of relative levels of vimentin-positive cells within the $\mathrm{CD} 45^{+}$population in bone marrow and peripheral blood is shown. $n=5$. ${ }^{*} P<0.05$.

\section{Myocardial Resident Cells Produce CTGF in Response to AngII}

In addition to cardiomyocytes, myocardial tissue contains large numbers of endothelial cells as a result of its rich capillary blood supply. Given our evidence that CTGF production was up-regulated in the myocardium before fibrocyte migration and seemed to be localized to resident cells, we sought to confirm that cardiomyocytes or endothelial cells produce CTGF after AngII exposure. To achieve this, we conducted in vitro stimulation assays using isolated neonatal cardiac myocytes and microvascular endothelial cells. Most of the isolated cardiomyocytes stained positive for CTnI, both at flow cytometry (97\%) and immunofluorescence (94\%), suggesting high purity (Figure 4, A and B). Stimulation of isolated cardiomyocytes for 6 hours with AngII significantly increased CTGF mRNA expression 2.1-fold when compared with vehicle-only control $(P<$ $0.05)$. The addition of neutralizing anti-TGF- $\beta$ antibody in combination with AngII exposure abrogated the increase in CTGF expression in vitro, which suggested that the change in expression was TGF- $\beta$-dependent (Figure 4C). This finding confirms that cardiomyocytes are capable of producing significant amounts of CTGF in response to AngII.
Similarly, endothelial cells significantly increased CTGF mRNA expression 2.8-fold after 6 hours of AngII exposure in vitro when compared with saline control. Again the increase in CTGF mRNA noted after AngII exposure was abrogated by the addition of neutralizing anti-TGF- $\beta$ antibody $(P<0.05)$ (Figure 5$)$. Together, these data provide supporting evidence that resident cells are responsible for the observed early peak in CTGF expression in response to AngII. Furthermore, this up-regulation in CTGF remains dependent on TGF- $\beta$ signaling, as demonstrated by the inhibitory effects of TGF- $\beta$ neutralizing antibody.

\section{Fibrocytes Isolated and Cultured in Vitro from AngII-Exposed Myocardium also Contribute to CTGF Expression}

While our findings suggest that CTGF is produced initially by resident cells, they may not explain our observation in vivo of a second peak in CTGF mRNA expression that seems to coincide with the increase in fibrocyte accumulation in the myocardium at 24 hours of AngII exposure. Therefore, we examined the possibility that infiltrating cells could also contribute to the high level of CTGF found in whole tissue after AngII exposure. Infiltrating fibrocytes (after AngII exposure) were isolated as previously described. ${ }^{9}$ Fibrocyte purity was assessed by confirming co-expression of the mesenchymal marker COL1 and the hematopoietic marker CD45 (Figure 6A). Using this approach, the mean purity of fibrocyte cultures was 50\%. Control animals yielded less than $1 \%$ fibrocytes (Figure 6B). Direct exposure of the isolated fibrocyte population to AngII resulted in a significant 2.6fold increase in CTGF mRNA expression when compared with saline control, which was reduced to saline control levels by the addition of neutralizing anti-TGF- $\beta$ antibody $(P<0.05)$ (Figure 6C). This suggests that a fibrocyte-rich population in which no cardiomyocytes are present is also capable of CTGF up-regulation and expression. These findings may explain the observed second peak in CTGF mRNA that we observed in the myocardium of animals after 24 hours of AngII exposure.

\section{Fibrocytes Proliferate in Response to CTGF}

We next focused on a potential role for CTGF in fibrocyte accumulation and ECM deposition. On examination of histologic sections from animals exposed to AngII for 3 days, we observed significant positive staining of Ki-67, a proliferation marker, in areas of fibrocyte infiltration when compared with saline control (Figure 7, A and B). This suggests that fibrocyte accumulation depends on both influx from the circulation and from proliferation. Fibrocyte proliferation in the myocardium occurred concurrently with the increase in CTGF. Thus, we investigated the effect of CTGF exposure on the proliferation of fibrocytes in vitro. Isolated fibrocytes exposed to CTGF resulted in significant 

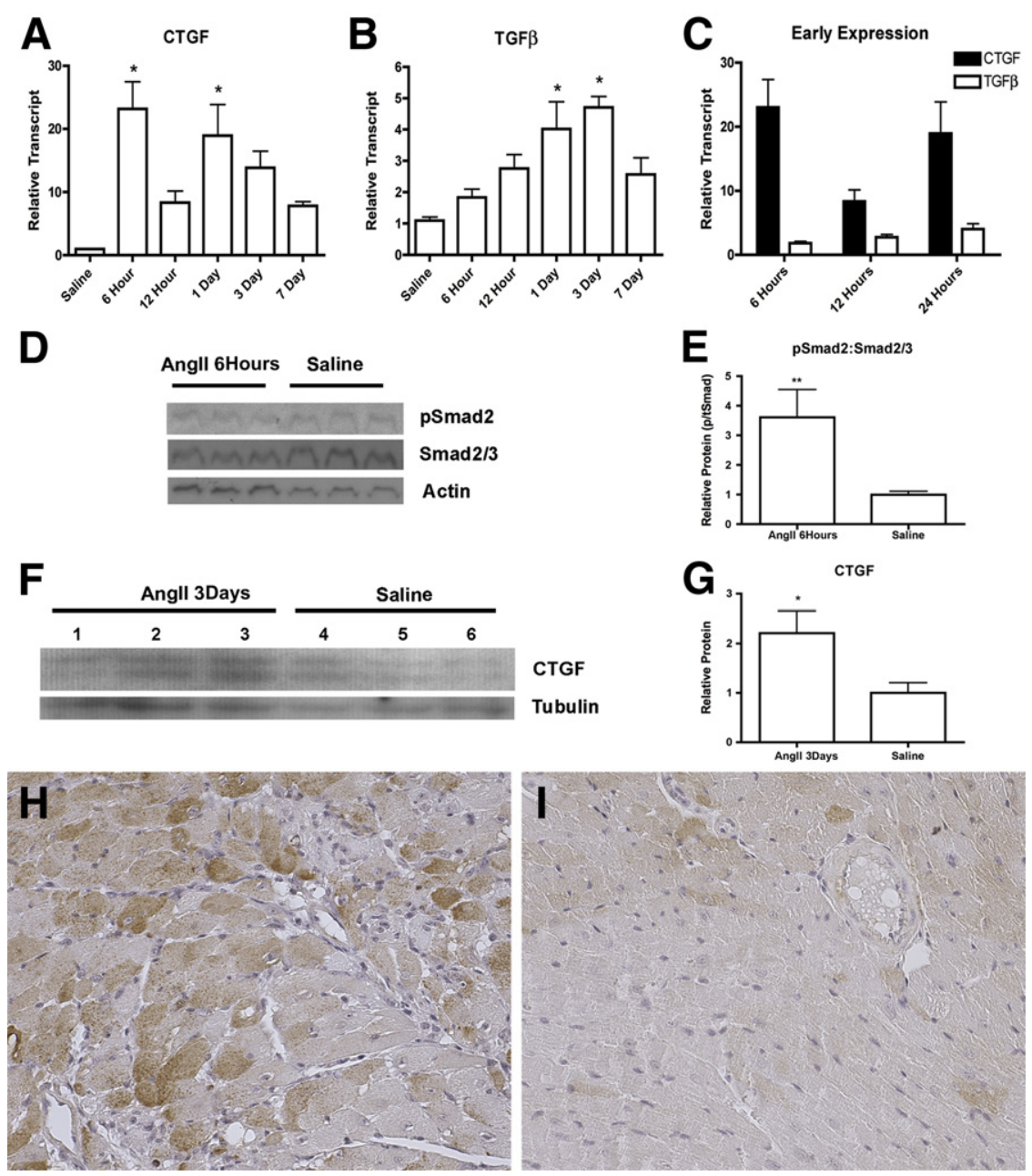

proliferation as assessed by $\mathrm{Ki}-67$ positivity when compared with media control $(P<0.05)$ (Figure 7C). This was confirmed using a second proliferation assay, the MTT assay $(P<0.05)$ (Figure 7D). These data suggest that increased fibrocyte proliferation within the myocardium after AngII exposure for 3 days is in part due to the increase in CTGF observed at this time.

\section{Fibrocytes Differentiate to ECM-Producing Cells Under the Influence of CTGF}

To investigate the effect of CTGF on fibrocyte differentiation, fibrocytes were isolated as previously described, and were exposed to CTGF. There was a significant increase in mRNA expression of COL1A1, with a 2.3-fold increase compared with saline control (Figure 8A). This suggests that the fibrocytes can become a source of ECM in the myocardium under appropriate conditions, in particular after AngII exposure and in the presence of CTGF. Inasmuch as we have demonstrated that AngII up-regulates expression of CTGF (Figure 6), this would create a positive feedback loop promoting a profibrotic environment.

Fibrocytes isolated from peripheral blood were enriched over 14 days with or without CTGF. Cells that were not exposed to CTGF over the duration had a significantly lower $\alpha$-SMA/CD133 ratio compared with early isolates (1 day). In contrast, fibrocytes exposed to CTGF during the 14-day enrichment did not show a significant reduction in $\alpha$-SMA/CD133 (Figure 8B). This suggests that CTGF exposure may enable fibrocytes to maintain higher mesenchymal protein expression and, therefore, favor differentiation of fibrocytes into ECM-producing myofibroblast-like cells.

CTGF increases the motility and migration of several types of cancer cells and vascular endothelial cells; however, this effect has yet to be evaluated with fibrocytes. ${ }^{33-35}$ Using a well-described scratch assay, CTGF resulted in a nonsignificant 1.02-fold change in recovered distance when compared with media control (Figure 9), which suggests that CTGF failed to affect the motility of isolated fibrocytes.

\section{Discussion}

Bone Marrow-Derived Progenitor Cells Mobilize and Migrate to Myocardium

We have previously reported that fibrocytes, a bone marrowderived fibroblast progenitor population, represent most of 

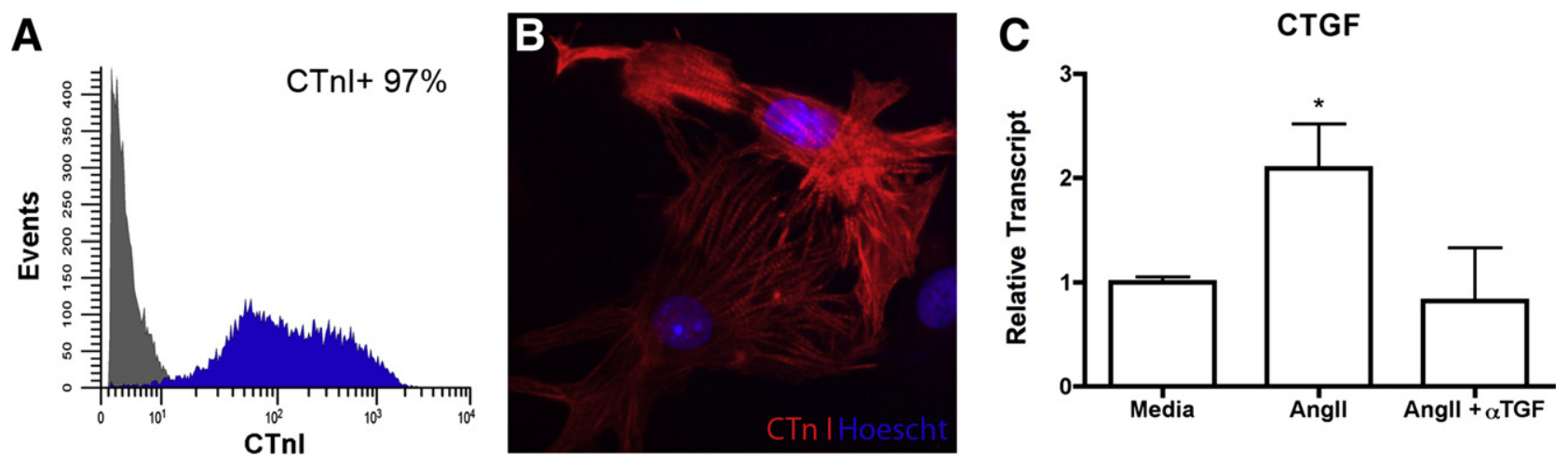

Figure 4 Cardiomyocytes produce CTGF. Cardiomyocytes were isolated from neonatal mice. Purity was assessed using CTnI staining by flow cytometry (A) and immunofluoresence with nuclei counterstained with Hoescht stain (B). C: Cultured cardiomyoctes were stimulated with AngII, AngII plus neutralizing anti-TGF- $\beta$ antibody ( $\alpha \mathrm{TGF}$ ), or saline control for 6 hours. CTGF mRNA expression was assessed using real-time qPCR and compared with the housekeeping gene 18S. Original magnification $\times 63 . n=8 ;{ }^{*} P<0.05$.

the infiltrating cells that accumulate in the myocardium after AngII exposure. ${ }^{9,31}$ The effector role of fibrocytes has been suggested in many fibrotic diseases including models of cardiomyopathy, ${ }^{11,36}$ cardiac hypertrophy, ${ }^{27}$ pulmonary fibrosis, ${ }^{15}$ and renal fibrosis. ${ }^{6}$ Strategies with the objective of eliminating fibrocytes have resulted in inhibition of development of myocardial fibrosis, supporting the causal relationship between fibrocytes and myocardial fibrosis. ${ }^{37-39}$ In the present study, we demonstrated that after 3 days of AngII exposure, cells that have migrated to the myocardium are bone marrow-derived $\left(\mathrm{GFP}^{+}\right)$and stain positive for the progenitor marker CD133 and mesenchymal markers $\alpha$-SMA or COL1, which confirms that the infiltrating cells are fibrocytes. We have also provided evidence that fibrocyte numbers increase in peripheral blood after AngII exposure, which supports a hypothesis of mobilization of these progenitor cells from the bone marrow in response to AngII. Given these findings, we investigated the parameters that induce fibrocyte accumulation in the myocardium and the propagation of the fibrotic response.

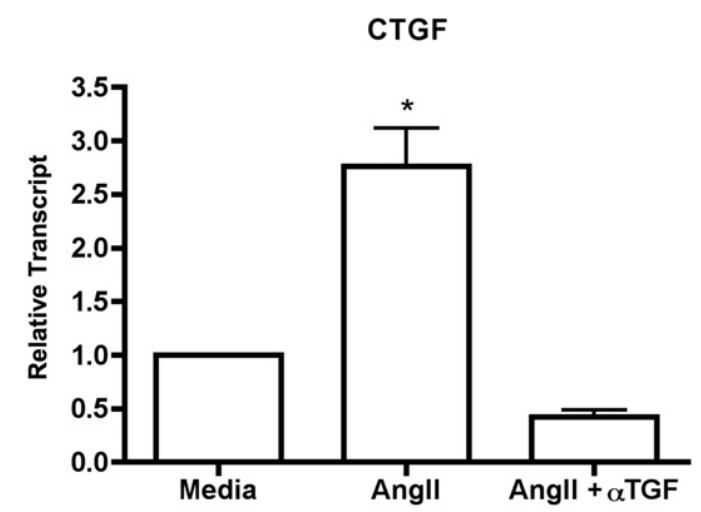

Figure 5 Microvascular endothelial cells produce CTGF. End3 endothelial cells were stimulated with AngII, AngII plus neutralizing anti-TGF$\beta$ antibody ( $\alpha \mathrm{TGF}$ ), or saline control for 6 hours. CTGF mRNA expression was assessed using real-time qPCR and compared with the housekeeping gene 18S. $n=3 ;{ }^{*} P<0.05$.
Fibrotic Mediators, the Interaction Between CTGF and TGF- $\beta$

We observed significant increases in CTGF mRNA and protein in the myocardium, well before the accumulation of fibrocytes, which suggests a link between CTGF production by resident cells and fibrocyte accumulation. Immunocytochemistry labeling for CTGF suggested that cardiomyocytes are a significant cellular source of CTGF. Further support for this hypothesis came from experiments using cultured cardiomyocytes, which demonstrated that AngII exposure results in significant increase in CTGF mRNA expression. Microvascular endothelial cells were also able to produce CTGF mRNA in response to AngII, which suggests that other resident myocardial cells contribute to the early increase in CTGF mRNA in vivo. The importance of CTGF in fibrosis development has been suggested by others, and a link between AngII and CTGF has been implicated by data showing that CTGF expression could be abrogated in animal models by angiotensin receptor blockade. ${ }^{40}$ These data suggest that the initial increase in CTGF expression seen in our model after AngII exposure was a direct result of signaling by resident cardiomyocytes and endothelial cells, which represent a large percentage of all myocardial cells. ${ }^{41}$

Traditionally, CTGF is believed to be regulated via TGF- $\beta$ signaling. CTGF was first described as a TGF- $\beta$ response factor in human umbilical vein endothelial cells and was found to be expressed by cultured skin fibroblasts in response to TGF- $\beta$ as early as 30 minutes after exposure. ${ }^{42,43}$ The role of TGF- $\beta$ as a key regulator of fibrosis development has previously been described and explains why there was an increase in TGF- $\beta$ mRNA in the myocardium after 1 day of exposure in the AngII infusion model. ${ }^{18,19} \mathrm{We}$ provide evidence for the first time that in a mouse model of AngII exposure, CTGF is expressed first ( 6 hours) within the myocardium by resident cells including cardiomyocytes and endothelial cells, well before the observed increase in TGF- $\beta$ expression (1 day). 

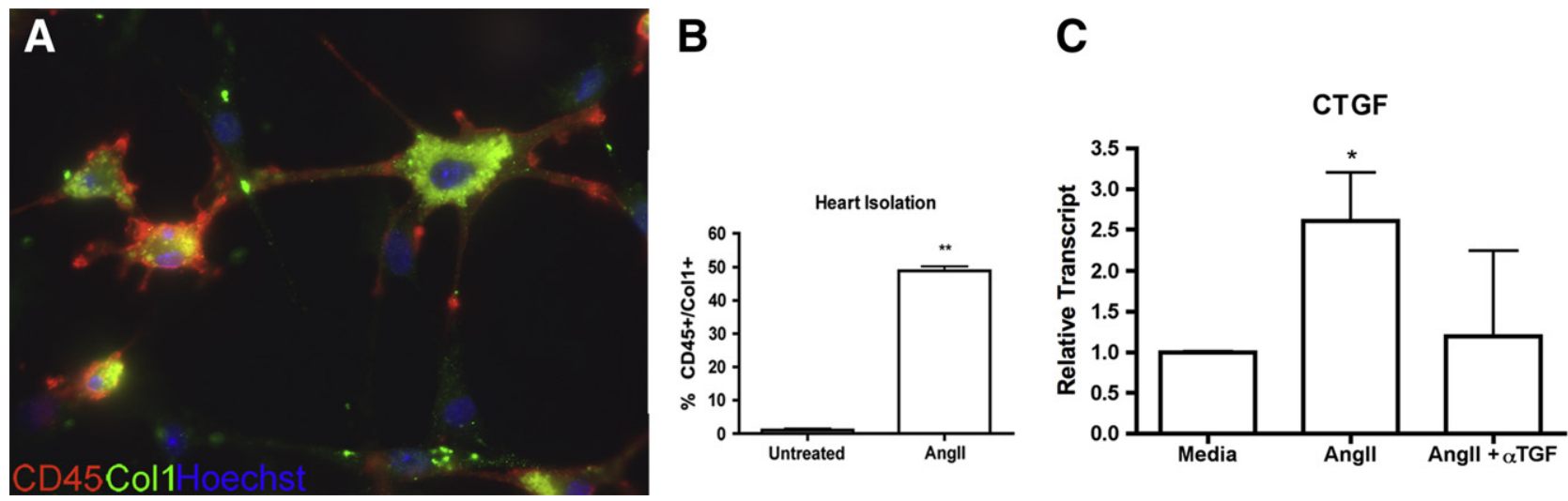

Figure 6 Isolated fibrocytes produce CTGF. A: Fibrocytes were isolated from the myocardium of mice exposed to AngII for 3 days. Purity was assessed via immunofluorescent staining for $\mathrm{CD}_{4} 5^{+} / \mathrm{COL}^{+}$, with nuclei counterstained with Hoescht stain. B: Purity was quantified by calculating the percentage of $\mathrm{CD}_{4} 5^{+} / \mathrm{COL} 1^{+}$cells relative to the total number of nuclei. Isolated fibrocytes were stimulated with AngII, AngII plus anti-TGF- $\beta$ neutralizing antibody ( $\alpha \mathrm{TGF}$, or saline control for 6 hours. C: CTGF mRNA expression was assessed using real-time qPCR and compared with the housekeeping gene 18S. Original magnification $\times 63 . n=5$. ${ }^{*} P<0.05,{ }^{* *} P<0.01$.

Whereas TGF- $\beta$ mRNA was not up-regulated until 1 day of AngII exposure, earlier TGF- $\beta$ signaling was likely the result of activation of latent TGF- $\beta$ protein, with dissociation of the latency-associated polypeptide, resulting in the early (6 hours) increase in CTGF mRNA expression detected. ${ }^{44}$ Once TGF- $\beta$ is activated, it binds the TGF- $\beta$ receptors, leading to a conformational change that results in kinase activity of the receptor. ${ }^{45}$ Ultimately, this results in phosphorylation of Smad2, which when complexed with Smad3 and co-Smad4 translocate to the nucleus and regulate expression of CTGF mRNA. ${ }^{21}$ We have provided novel supporting evidence that Smad2 phosphorylation increases early, by 6 hours of AngII infusion in vivo. This was concurrent with the increase in early CTGF mRNA observed at 6 hours. Together with our in vitro observation that CTGF expression after AngII exposure seems to be TGF- $\beta$-dependent, this suggests that AngII exposure resulted in early TGF- $\beta$ activation with downstream phosphorylation of Smad2, which was responsible for the observed increase in CTGF mRNA expression. This is supported by the evidence that AngII-induced ECM synthesis can be limited by TGF- $\beta$ neutralizing antibody or truncated TGF- $\beta$ type II receptors. ${ }^{46}$

During the course of AngII exposure, the initial increase in CTGF expression was followed by a reduction in CTGF mRNA at 12 hours. At 24 hours, CTGF expression in the myocardium rebounded, coinciding with increased infiltration of fibrocytes.

We demonstrated that fibrocytes enriched in culture upregulate CTGF expression in response to AngII exposure, providing convincing evidence that fibrocytes could be

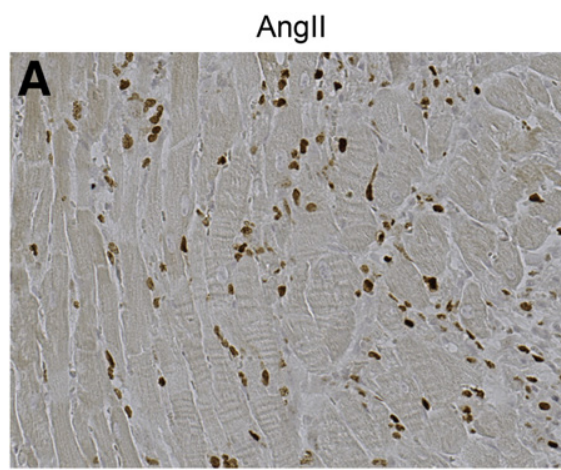

C

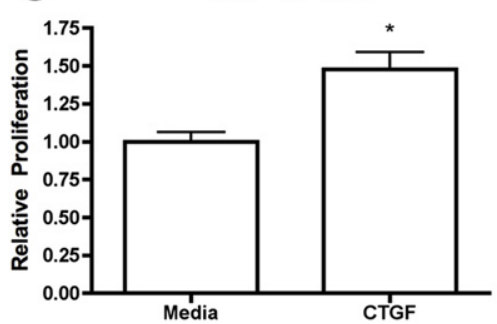

Saline
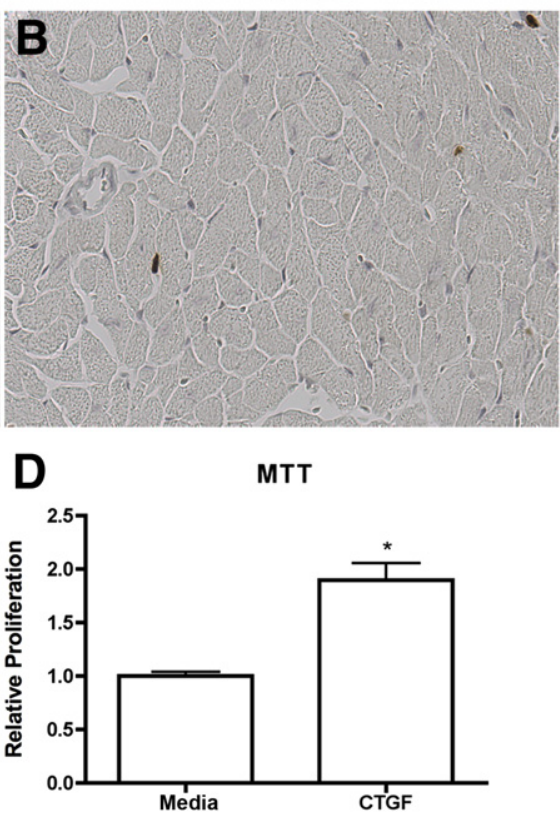

Figure 7 Fibrocytes proliferate in response to CTGF. Immunohistochemistry was used to identify Ki-67-positive cells within the myocardium of animals exposed to AngII (A) or saline control (B) for 3 days. Isolated fibrocytes were exposed to CTGF or vehicle control for 24 hours. Proliferation was assessed by counting cells positive for immunofluorescent staining of $\mathrm{Ki}-67$ relative to the number of nuclei in five fields of view per sample captured at $\times 25$ magnification (C) and MTT assay (D). Original magnification $\times 40 . n=6$; $* P<0.05$. 
A

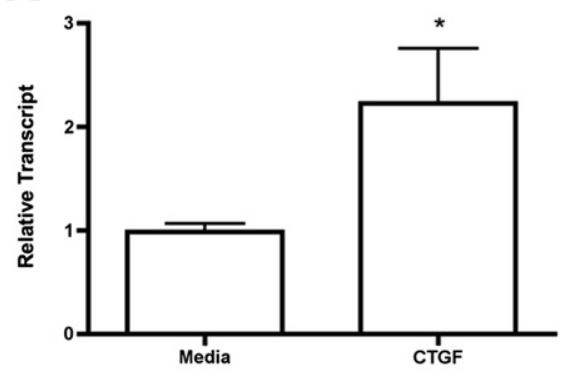

B

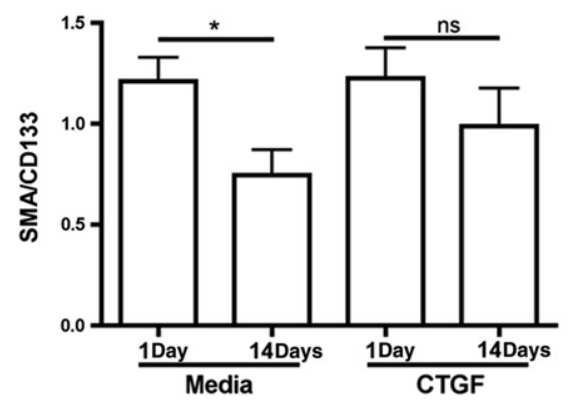

CTGF Regulation of Fibrocyte Proliferation and ECM Production

The timing of CTGF expression in the myocardium suggested that CTGF has an important role in the early environment that leads to myocardial fibrosis after AngII exposure. Inasmuch as fibrocytes are the predominant infiltrating cell type in the myocardium after AngII exposure, ${ }^{9}$ and many fibrotic conditions feature CTGF up-regulation, it follows that CTGF may promote fibrosis by acting on fibrocytes. In our AngII model, we demonstrated that fibrocytes in the myocardium were highly proliferative. Thus, we believed CTGF might promote fibrosis through fibrocyte proliferation because CTGF minimally affected the motility of cultured fibrocytes. Several studies have provided evidence supporting this theory by demonstrating that CTGF increases proliferation in cultured fibroblasts. ${ }^{48,49} \mathrm{We}$,

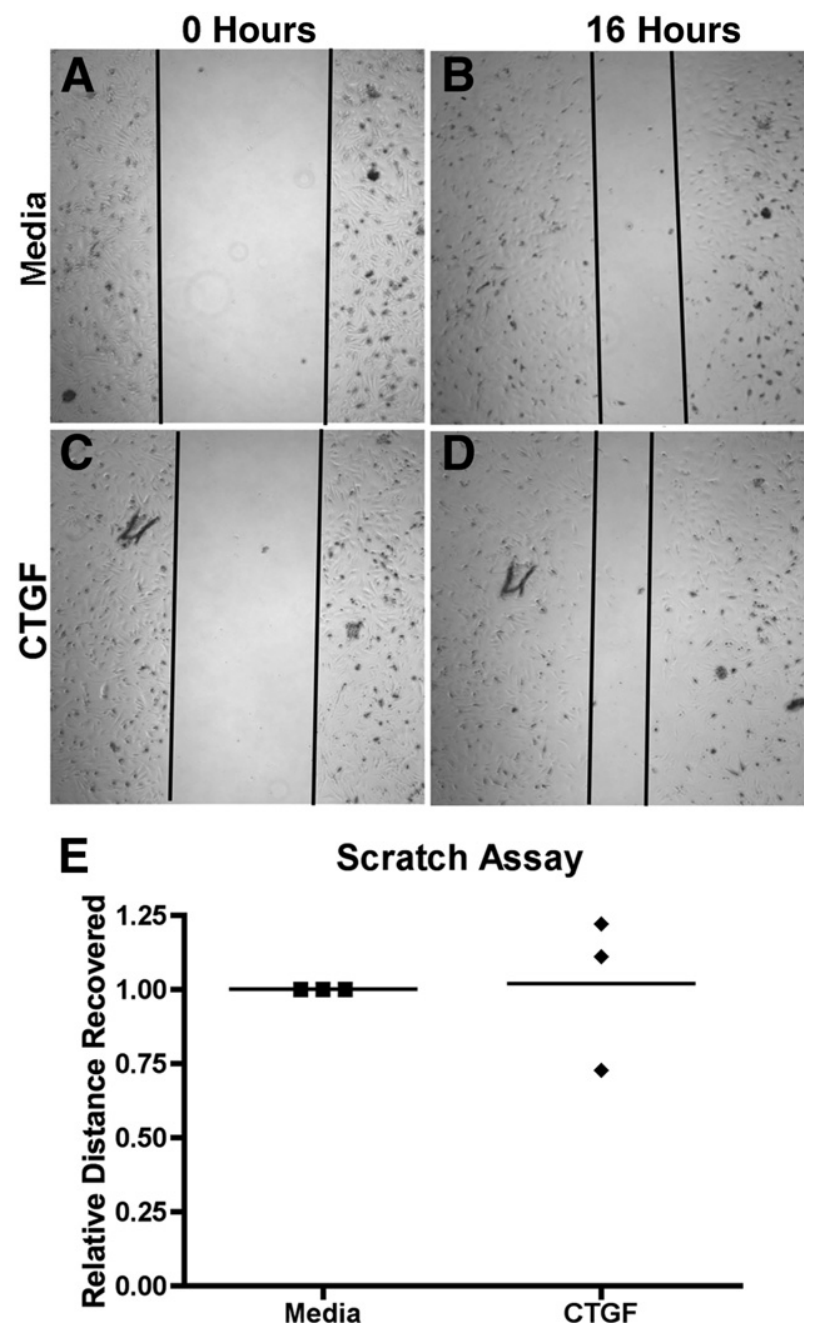

Figure 9 CTGF does not affect the mobility of isolated fibrocytes. Isolated fibrocytes were cultured and scrapped from a section of the plate. Images captured immediately (0 hours; $\mathbf{A}$ and $\mathbf{C}$ ) or after 16 hours (B and $\mathbf{D}$ ) of culture in media containing either PBS (A and $\mathbf{B}$ ) as control or CTGF (C and D). A-D: Original magnification $\times 10$. E: Pixel counts were used to semiquantify the relative distance recovered compared with initial scratch size. $n=3$. 
therefore, investigated the effects of CTGF on isolated fibrocytes in culture. Consistent with our in vivo findings, CTGF exposure led to increased fibrocyte proliferation in vitro. This suggests that the increase in CTGF production in the myocardium after AngII exposure contributed to the observed increase in fibrocyte accumulation within the myocardium by increasing fibrocyte proliferation.

Fibrocytes are progenitor cells that under certain conditions are capable of differentiation into collagen-producing myofibroblasts. We sought to investigate the effect of CTGF on the maturation and differentiation of fibrocytes. We have provided evidence for the first time that fibrocyte-enriched cell culture exposed to CTGF resulted in a significant increase in COL1A1 mRNA, supporting the differentiation of fibrocytes toward an ECM-producing phenotype. In support of our observation, some investigators have shown increased expression of ECM proteins by fibroblasts after exposure to CTGF. ${ }^{12,50}$ Furthermore, there is also evidence that suggests that inhibiting CTGF in vitro is sufficient to reduce COL 1 and $\alpha$-SMA protein production by stimulated fibroblast cell lines and primary isolated fibroblasts, thus supporting a role for CTGF in promoting and maintaining fibroblast differentiation and phenotype. ${ }^{48,50,51}$

Together, our results suggest that CTGF is involved in the regulation of myocardial fibrosis after AngII exposure. We have provided two mechanisms by which CTGF contributes to the profibrotic microenvironment: increased fibrocyte proliferation contributing to fibrocyte accumulation and promotion of fibrocyte differentiation into ECM-producing cells.

\section{Mechanism of Action of CTGF}

A CTGF receptor has not yet been identified; thus, the molecular mechanisms of action continue to be investigated. Although the exact molecular mechanisms of CTGF signaling are beyond the scope of the present study, a number of possible pathways may be involved in regulation of ECM production and cellular proliferation in response to CTGF. In support of this hypothesis, separate domains of CTGF have been suggested as responsible for regulating proliferation or differentiation. ${ }^{48}$ One possible pathway that is likely involved is the mitogen-activated protein kinase cascades, specifically $\mathrm{p} 38$, which is involved in regulating proliferation and COL1 expression. ${ }^{52}$ Indeed, p38 positively regulates COL1A1 expression by primary fibroblasts and is significantly phosphorylated after cells are exposed to CTGF. ${ }^{53}$ Moreover, exposure to CTGF results in reduced phosphorylation of mitogen-activated protein kinases ERK1/2 and JNK, which have been suggested to repress COL1A1 expression, resulting in increased COL1A1 expression when CTGF is present. ${ }^{53,54}$ Together, these studies suggest that activation of the p38 mitogen-activated protein kinase pathway in combination with repression of the ERK1/2 and JNK pathways could control COL1A1 expression and proliferation of fibrocytes in response to CTGF.
Although mice constitutively lacking CTGF die shortly after birth, ${ }^{55}$ antifibrotic intervention through blockade of CTGF has shown some positive results in animal models of skin, kidney, and lung fibrosis. ${ }^{56-58}$ Potential strategies for interrupting the effects of CTGF were thoroughly reviewed by Brigstock ${ }^{59}$ and included monoclonal antibody, antisense oligonucleotide, and siRNA interventions. Preliminary results published from recent stage 1 clinical trials have suggested that a humanized anti-CTGF antibody decreased kidney failure in a cohort of patients with diabetic nephropathy. ${ }^{60}$ These potential therapeutic strategies, however, have not yet been successfully deployed for the treatment of myocardial fibrosis. ${ }^{59}$ With this in mind, we provide evidence that CTGF contributes to the proliferation of fibrocytes and may have autocrine effects, which could be necessary to promote the profibrotic environment required for development of myocardial fibrosis as opposed to myocardial healing. We have provided support for a profibrotic role for CTGF in development of myocardial fibrosis after AngII exposure downstream of TGF- $\beta$, conceivably enabling the opportunity to interrupt the fibrotic role of TGF- $\beta$ without affecting its immunomodulatory properties. Thus, CTGF may still present a therapeutic target for reducing fibrosis in cardiac diseases, although this requires further evaluation.

\section{Acknowledgment}

We thank Tanya Myers for technical expertise.

\section{References}

1. Berk BC, Fujiwara K, Lehoux S: ECM remodeling in hypertensive heart disease. J Clin Invest 2007, 117:568-575

2. Gurtner GC, Werner S, Barrandon Y, Longaker MT: Wound repair and regeneration. Nature 2008, 453:314-321

3. Sun Y: Intracardiac renin-angiotensin system and myocardial repair/ remodeling following infarction. J Mol Cell Cardiol 2010, 48 : 483-489

4. Wynn TA: Cellular and molecular mechanisms of fibrosis. J Pathol 2008, 214:199-210

5. Mervaala E, Muller DN, Schmidt F, Park JK, Gross V, Bader M, Breu V, Ganten D, Haller H, Luft FC: Blood pressure-independent effects in rats with human renin and angiotensinogen genes. Hypertension 2000, 35:587-594

6. Sakai N, Wada T, Matsushima K, Bucala R, Iwai M, Horiuchi M, Kaneko $\mathrm{S}$ : The renin-angiotensin system contributes to renal fibrosis through regulation of fibrocytes. J Hypertens 2008, 26:780-790

7. Kai H, Kudo H, Takayama N, Yasuoka S, Kajimoto H, Imaizumi T: Large blood pressure variability and hypertensive cardiac remodeling: role of cardiac inflammation. Circ J 2009, 73:2198-2203

8. Sun Y: Myocardial repair/remodelling following infarction: roles of local factors. Cardiovasc Res 2009, 81:482-490

9. Sopel MJ, Rosin NL, Lee TD, Legare JF: Myocardial fibrosis in response to Angiotensin II is preceded by the recruitment of mesenchymal progenitor cells. Lab Invest 2010, 91:565-578

10. Haudek SB, Cheng J, Du J, Wang Y, Hermosillo-Rodriguez J, Trial J, Taffet GE, Entman ML: Monocytic fibroblast precursors mediate fibrosis in angiotensin-II-induced cardiac hypertrophy. J Mol Cell Cardiol 2010, 49:499-507 
11. Chu PY, Mariani J, Finch S, McMullen JR, Sadoshima J, Marshall T, Kaye DM: Bone marrow-derived cells contribute to fibrosis in the chronically failing heart. Am J Pathol 2010, 176:1735-1742

12. Abe R, Donnelly SC, Peng T, Bucala R, Metz CN: Peripheral blood fibrocytes: differentiation pathway and migration to wound sites. J Immunol 2001, 166:7556-7562

13. Pilling D, Fan T, Huang D, Kaul B, Gomer RH: Identification of markers that distinguish monocyte-derived fibrocytes from monocytes, macrophages, and fibroblasts. PLoS One 2009, 4:e7475

14. Kisseleva T, Uchinami H, Feirt N, Quintana-Bustamante O, Segovia JC, Schwabe RF, Brenner DA: Bone marrow-derived fibrocytes participate in pathogenesis of liver fibrosis. J Hepatol 2006, 45: 429-438

15. Andersson-Sjoland A, de Alba CG, Nihlberg K, Becerril C, Ramirez R, Pardo A, Westergren-Thorsson G, Selman M: Fibrocytes are a potential source of lung fibroblasts in idiopathic pulmonary fibrosis. Int J Biochem Cell Biol 2008, 40:2129-2140

16. Wang JF, Jiao H, Stewart TL, Shankowsky HA, Scott PG, Tredget EE: Fibrocytes from burn patients regulate the activities of fibroblasts. Wound Repair Regen 2007, 15:113-121

17. Roderfeld M, Rath T, Voswinckel R, Dierkes C, Dietrich H, Zahner D, Graf J, Roeb E: Bone marrow transplantation demonstrates medullar origin of $\mathrm{CD} 34+$ fibrocytes and ameliorates hepatic fibrosis in Abcb4-/- mice. Hepatology 2010, 51:267-276

18. Ruiz-Ortega M, Rodriguez-Vita J, Sanchez-Lopez E, Carvajal G, Egido J: TGF-beta signaling in vascular fibrosis. Cardiovasc Res 2007, 74:196-206

19. Rosenkranz S: TGF-betal and angiotensin networking in cardiac remodeling. Cardiovasc Res 2004, 63:423-432

20. Chen MM, Lam A, Abraham JA, Schreiner GF, Joly AH: CTGF expression is induced by TGF-beta in cardiac fibroblasts and cardiac myocytes: a potential role in heart fibrosis. J Mol Cell Cardiol 2000, 32:1805-1819

21. Yang F, Chung AC, Huang XR, Lan HY: Angiotensin II induces connective tissue growth factor and collagen I expression via transforming growth factor-beta-dependent and -independent Smad pathways: the role of Smad3. Hypertension 2009, 54:877-884

22. Huang XR, Chung AC, Yang F, Yue W, Deng C, Lau CP, Tse HF, Lan HY: Smad3 mediates cardiac inflammation and fibrosis in angiotensin II-induced hypertensive cardiac remodeling. Hypertension 2010, 55:1165-1171

23. Sonnylal S, Shi-Wen X, Leoni P, Naff K, Van Pelt CS, Nakamura H, Leask A, Abraham D, Bou-Gharios G, de Crombrugghe B: Selective expression of connective tissue growth factor in fibroblasts in vivo promotes systemic tissue fibrosis. Arthritis Rheum 2010, 62: $1523-1532$

24. Shi-Wen X, Leask A, Abraham D: Regulation and function of connective tissue growth factor/CCN2 in tissue repair, scarring and fibrosis. Cytokine Growth Factor Rev 2008, 19:133-144

25. Daniels A, van Bilsen M, Goldschmeding R, van der Vusse GJ, van Nieuwenhoven FA: Connective tissue growth factor and cardiac fibrosis. Acta Physiol (Oxf) 2009, 195:321-338

26. Gonzalez A, Lopez B, Ravassa S, Beaumont J, Arias T, Hermida N, Zudaire A, Diez J: Biochemical markers of myocardial remodelling in hypertensive heart disease. Cardiovasc Res 2009, 81:509-518

27. Endo J, Sano M, Fujita J, Hayashida K, Yuasa S, Aoyama N, Takehara Y, Kato O, Makino S, Ogawa S, Fukuda K: Bone marrow derived cells are involved in the pathogenesis of cardiac hypertrophy in response to pressure overload. Circulation 2007, 116:1176-1184

28. Wang GW, Kang YJ: Inhibition of doxorubicin toxicity in cultured neonatal mouse cardiomyocytes with elevated metallothionein levels. J Pharmacol Exp Ther 1999, 288:938-944

29. Marshall RP, McAnulty RJ, Laurent GJ: Angiotensin II is mitogenic for human lung fibroblasts via activation of the type 1 receptor. Am J Respir Crit Care Med 2000, 161:1999-2004

30. Wolf G, Mueller E, Stahl RA, Ziyadeh FN: Angiotensin II-induced hypertrophy of cultured murine proximal tubular cells is mediated by endogenous transforming growth factor-beta. J Clin Invest 1993, 92 : $1366-1372$

31. Sopel M, Falkenham A, Oxner A, Ma I, Lee TD, Legare JF: Fibroblast progenitor cells are recruited into the myocardium prior to the development of myocardial fibrosis. Int J Exp Pathol 2012, 93:115-124

32. He Z, Way KJ, Arikawa E, Chou E, Opland DM, Clermont A, Isshiki K, Ma RC, Scott JA, Schoen FJ, Feener EP, King GL: Differential regulation of angiotensin II-induced expression of connective tissue growth factor by protein kinase $\mathrm{C}$ isoforms in the myocardium. J Biol Chem 2005, 280:15719-15726

33. Shimo T, Nakanishi T, Nishida T, Asano M, Kanyama M, Kuboki T, Tamatani T, Tezuka K, Takemura M, Matsumura T, Takigawa M: Connective tissue growth factor induces the proliferation, migration, and tube formation of vascular endothelial cells in vitro, and angiogenesis in vivo. J Biochem 1999, 126:137-145

34. Chen PS, Wang MY, Wu SN, Su JL, Hong CC, Chuang SE, Chen MW, Hua KT, Wu YL, Cha ST, Babu MS, Chen CN, Lee PH, Chang KJ, Kuo ML: CTGF enhances the motility of breast cancer cells via an integrin-alphavbeta3-ERK1/2-dependent S100A4-upregulated pathway. J Cell Sci 2007, 120:2053-2065

35. Aguiar DP, Pontes B, Mendes FA, Andrade LR, Viana NB, Abreu JG: CTGF/CCN2 has a chemoattractive function but a weak adhesive property to embryonic carcinoma cells. Biochem Biophys Res Commun 2011, 413:582-587

36. Haudek SB, Xia Y, Huebener P, Lee JM, Carlson S, Crawford JR, Pilling D, Gomer RH, Trial J, Frangogiannis NG, Entman ML: Bone marrow-derived fibroblast precursors mediate ischemic cardiomyopathy in mice. Proc Natl Acad Sci U S A 2006, 103:18284-18289

37. Sopel MJ, Rosin NL, Lee TDG, Légaré JF: Myocardial fibrosis in response to Angiotensin II is preceded by the recruitment of mesenchymal progenitor cells. Lab Invest 2010, 91:565-578

38. Haudek SB, Cheng J, Du J, Wang Y, Hermosillo-Rodriguez J, Trial J, Taffet GE, Entman ML: Monocytic fibroblast precursors mediate fibrosis in angiotensin-II-induced cardiac hypertrophy. J Mol Cell Cardiol 2010, 49:499-507

39. Chu PY, Mariani J, Finch S, McMullen JR, Sadoshima J, Marshall T, Kaye DM: Bone marrow-derived cells contribute to fibrosis in the chronically failing heart. Am J Pathol 2010, 176:1735-1742

40. Rupèrez M, Lorenzo O, Blanco-Colio LM, Esteban V, Egido J, RuizOrtega M: Connective tissue growth factor is a mediator of angiotensin II-induced fibrosis. Circulation 2003, 108:1499-1505

41. Suzuki J, Matsubara H, Urakami M, Inada M: Rat angiotensin II (type 1A) receptor mRNA regulation and subtype expression in myocardial growth and hypertrophy. Circ Res 1993, 73:439-447

42. Igarashi A, Okochi H, Bradham DM, Grotendorst GR: Regulation of connective tissue growth factor gene expression in human skin fibroblasts and during wound repair. Mol Biol Cell 1993, 4: 637-645

43. Bradham DM, Igarashi A, Potter RL, Grotendorst GR: Connective tissue growth factor: a cysteine-rich mitogen secreted by human vascular endothelial cells is related to the SRC-induced immediate early gene product CEF-10. J Cell Biol 1991, 114:1285-1294

44. Hao J, Wang B, Jones SC, Jassal DS, Dixon IM: Interaction between angiotensin II and Smad proteins in fibroblasts in failing heart and in vitro. Am J Physiol Heart Circ Physiol 2000, 279:H3020-H3030

45. Shi Y, Massagué J: Mechanisms of TGF-beta signaling from cell membrane to the nucleus. Cell 2003, 113:685-700

46. Koitabashi N, Danner T, Zaiman AL, Pinto YM, Rowell J, Mankowski J, Zhang D, Nakamura T, Takimoto E, Kass DA: Pivotal role of cardiomyocyte TGF- $\beta$ signaling in the murine pathological response to sustained pressure overload. J Clin Invest 2011, 121:2301-2312

47. Wang Q, Usinger W, Nichols B, Gray J, Xu L, Seeley TW, Brenner M, Guo G, Zhang W, Oliver N, Lin A, Yeowell D: Cooperative interaction of CTGF and TGF-beta in animal models of fibrotic disease. Fibrogenesis Tissue Repair 2011, 4:4 
48. Grotendorst GR, Duncan MR: Individual domains of connective tissue growth factor regulate fibroblast proliferation and myofibroblast differentiation. FASEB J 2005, 19:729-738

49. Ahmed MS, Oie E, Vinge LE, Yndestad A, Oystein Andersen G, Andersson Y, Attramadal T, Attramadal H: Connective tissue growth factor: a novel mediator of angiotensin II-stimulated cardiac fibroblast activation in heart failure in rats. J Mol Cell Cardiol 2004, 36:393-404

50. Garrett Q, Khaw PT, Blalock TD, Schultz GS, Grotendorst GR, Daniels JT: Involvement of CTGF in TGF-beta1-stimulation of myofibroblast differentiation and collagen matrix contraction in the presence of mechanical stress. Invest Ophthalmol Vis Sci 2004, 45:1109-1116

51. Lee $\mathrm{CH}$, Shah B, Moioli EK, Mao JJ: CTGF directs fibroblast differentiation from human mesenchymal stem/stromal cells and defines connective tissue healing in a rodent injury model. J Clin Invest 2010, 120:3340-3349

52. Zhang W, Liu HT: MAPK signal pathways in the regulation of cell proliferation in mammalian cells. Cell Res 2002, 12:9-18

53. Sánchez-López E, Rayego S, Rodrigues-Díez R, Rodriguez JS, Rodriguez-Díez R, Rodriguez-Vita J, Carvajal G, Aroeira LS, Selgas R, Mezzano SA, Ortiz A, Egido J, Ruiz-Ortega M: CTGF promotes inflammatory cell infiltration of the renal interstitium by activating NF-kappaB. J Am Soc Nephrol 2009, 20:1513-1526

54. Reunanen N, Foschi M, Han J, Kahari VM: Activation of extracellular signal-regulated kinase 1/2 inhibits type I collagen expression by human skin fibroblasts. J Biol Chem 2000, 275:34634-34639
55. Ivkovic S, Yoon BS, Popoff SN, Safadi FF, Libuda DE, Stephenson RC, Daluiski A, Lyons KM: Connective tissue growth factor coordinates chondrogenesis and angiogenesis during skeletal development. Development 2003, 130:2779-2791

56. Ikawa Y, Ng PS, Endo K, Kondo M, Chujo S, Ishida W, Shirasaki F, Fujimoto M, Takehara K: Neutralizing monoclonal antibody to human connective tissue growth factor ameliorates transforming growth factor-beta-induced mouse fibrosis. J Cell Physiol 2008, 216: 680-687

57. Wang X, Wu G, Gou L, Liu Z, Fan X, Wu L, Liu N: A novel singlechain-Fv antibody against connective tissue growth factor attenuates bleomycin-induced pulmonary fibrosis in mice. Respirology 2011, 16 : 500-507

58. Yokoi H, Mukoyama M, Nagae T, Mori K, Suganami T, Sawai K, Yoshioka T, Koshikawa M, Nishida T, Takigawa M, Sugawara A, Nakao K: Reduction in connective tissue growth factor by antisense treatment ameliorates renal tubulointerstitial fibrosis. J Am Soc Nephrol 2004, 15:1430-1440

59. Brigstock DR: Strategies for blocking the fibrogenic actions of connective tissue growth factor $(\mathrm{CCN} 2)$ : from pharmacological inhibition in vitro to targeted siRNA therapy in vivo. J Cell Commun Signal 2009, 3:5-18

60. Adler SG, Schwartz S, Williams ME, Arauz-Pacheco C, Bolton WK, Lee T, Li D, Neff TB, Urquilla PR, Sewell KL: Phase 1 study of antiCTGF monoclonal antibody in patients with diabetes and microalbuminuria. Clin J Am Soc Nephrol 2010, 5:1420-1428 